\title{
Tras los hilos de Ariadna. Memorias y experiencias de formación en los laberintos de la literatura
}

Following Ariadne's Threads. Memories and Training Experiences in Literature Labyrinths

Derriere les fils d'Ariane. Memoires et experiences de formation dans les labyrinthes de la litterature

Atrás dos fios de Ariadna. Memórias e experiências de formação nos labirintos da literatura

Fecha de recepción: 18 DE JUNIO DE 2014 / Fecha de aceptación: 10 DE NOVIEMBRE DE 2014 / Fecha de disponibilidad en línea: 15 DE MARZO DE 2015

Encuentre este artículo en http://magisinvestigacioneducacion.javeriana.edu.co/

doi: 10.11144/Javeriana.M7-15.THAM

Escrito por Érica Areiza-Pérez Universidad de AntIOQUia MedelLín, Colombia ericaareiza@gmail.com

Diela Bibiana Betancur-Valencia UNIVERSIDAD DE ANTIOQUIA Medellín, Colombia diela11@gmail.com

\section{Resumen}

El texto pone el acento en tres aspectos fundamentales de la enseñanza y el aprendizaje de la literatura: la memoria literaria del maestro, la experiencia de los estudiantes en la relación con los libros y algunas estrategias que posibilitan el trabajo con la literatura en el escenario escolar; asimismo, contempla las posibilidades que esta ofrece para la apropiación de conocimiento, la construcción de subjetividad, el despliegue de la imaginación y la sensibilidad, la expresión de los sentidos, la exploración de la riqueza del lenguaje, la comprensión de la realidad y el posicionamiento crítico frente al mundo.

Palabras clave descriptor

Enseñanza de la literatura, memoria literaria, experiencia, escuela, formación.

\section{Transferencia a la práctica}

La enseñanza de la literatura continúa siendo una preocupación de los maestros en los distintos niveles educativos en los que se desenvuelven. Muchas veces esta genuina preocupación se pone en el afuera, en el hacer y en una gramática del deber que proscribe la subjetividad, con la memoria y la experiencia concomitantes. Sin embargo, es justamente en la subjetividad, en la memoria y en la experiencia del maestro en donde pueden hallarse los embriones de propuestas sensibles, oportunas, conmovedoras; propuestas que pongan la creatividad al servicio de la enseñanza, que partan de reconocer los saberes de los estudiantes y que conduzcan a una reinvención, siempre singular, única y cada vez renovable, del acto de educar.

Para citar este artículo / To cite this article / Pour citer cet article / Para citar este artigo Areiza-Pérez, E. \& Betancur-Valencia, D. B. (2015). Tras los hilos de Ariadna. Memorias y experiencias de formación en los laberintos de la literatura. magis, Revista Internacional de Investigación en Educación, 7 (15), 151-162. 
Key words plus

Literature Teaching, Literary Memory,

Experience, School, Teaching.
Mots clés descripteur

Enseignement de la littérature, mémoire littéraire, expérience, école, formation.

\section{Abstract}

The text focuses on three main aspects concerning the teaching and learning of literature, namely the literary memory of the teacher, the student experience in relation to books and some strategies that enable working with literature in the school setting It also contemplates the possibilities that it offers for knowledge acquisition, construction of subjectivity, imagination and sensitivity development, expression of the senses, exploration of the richness of language, understanding of reality and a critical position towards the world.

\section{Transfer to practice}

Literature teaching remains a concern for teachers in the different educational levels where they work. This genuine concern is often placed in the outside, in the making and within a grammar of duty which proscribes subjectivity, with memory and experience that are concomitants. However, it is precisely in the subjectivity, memory and experiences of the teacher where the motivations that give rise to sensitive, timely, and touching proposals can be found proposals which would enable creativity to serve education, by recognizing the knowledge of students, and leading to a reinvention, always singular, unique and increasingly renewable, of the act of teaching.

\section{Résumé}

Le texte met l'accent dans trois aspects fondamentaux par rapport à l'enseignement et l'apprentissage de la littérature, à savoir, la mémoire littéraire de l'enseignant, l'expérience des étudiants dans le rapport aux livres et quelques stratégies qui donnent la possibilité de travailler la littérature dans le domaine scolaire; de la même manière on contemple les possibilités qu'elle donne pour l'appropriation de la connaissance, la construction de la subjectivité, le déploiement de l'imagination et la sensibilité, l'expression des sens, l'exploration de la richesse du langage, la compréhension de la réalité et la posture critique face au monde.

\section{Transfert à la pratique}

L'enseignement de la littérature continue étant une préoccupation des enseignants dans les différents niveaux éducatifs dans lesquels ils travaillent. Plusieurs fois cette légitime préoccupation se pose dans le dehors, dans le faire et dans une grammaire du devoir qui proscrit la subjectivité, avec la mémoire et l'expérience qui vont ensembles. Cependant, c'est précisément dans la subjectivité, dans la mémoire et dans l'expérience de l'enseignant où I'on peut trouver les embryons de propositions sensibles, opportunes et touchantes; des propositions qui puissent mettre la créativité au service de l'enseignement, celles-ci partent de reconnaître les savoirs des étudiants qu'elles emmènent à une réinvention, toujours singulier, unique et à chaque fois rénovatrice de l'acte d'éduquer.

\section{Palavras-chave descritor}

Ensino da literatura, memória literária, experiência, escola, formação.

\section{Resumo}

O texto destaca três aspectos fundamentais da relação entre o ensino e a aprendizagem da literatura, a saber, a memória literária do mestre, a experiência dos estudantes na relação com os livros e algumas estratégias que possibilitam o trabalho com a literatura no contexto escolar. Da mesma forma contempla as possibilidades que esta oferece para a apropriação de conhecimento, a construção de subjetividade, o desenvolvimento da imaginação e da sensibilidade, a expressão dos sentidos, a exploração da riqueza da linguagem, o entendimento da realidade e o posicionamento crítico em frente ao mundo.

\section{Transferência à Prática}

O ensino da literatura continua sendo uma preocupação dos mestres nos diferentes níveis educativos nos quais se desenvolvem. Muitas vezes esta genuína preocupação se coloca do lado de fora, no fazer e em uma gramática do dever que proscreve a subjetividade, com a memória e a experiência que lhe são concomitantes. No entanto, é justamente na subjetividade, na memória e na experiência do mestre onde podem ser encontrados os embriões de propostas sensíveis, oportunas, comoventes; propostas que ponham a criatividade a serviço do ensino, que partam de reconhecer os saberes dos estudantes e que conduzam a uma reinvenção, sempre singular, única e cada vez renovável, do ato de educar. 


\section{Pasaporte a una ficción colectiva: importancia de la memoria literaria del maestro}

Que la medianoche nos sorprenda en nuestro tránsito por una ciudad de calles solitarias no es extraño, pero que en medio de ese vagabundeo nocturnal irrumpa un automóvil con personajes desconocidos que nos invitan a viajar a mundos literarios de épocas pasadas resulta tan insólito como enigmático. Esto es, literalmente, una experiencia de película. Pues es justamente lo que sucede en Medianoche en París, una producción cinematográfica escrita y dirigida por Woody Allen, donde Gil Pender, el protagonista de la cinta, es sorprendido por un vehículo cuyos ocupantes lo devuelven al París de los años veinte, a la época de sus autores preferidos. En virtud de ese retorno interactúa con escritores como Scott Fitzgerald, T. S. Eliott y Ernest Hemingway, y con artistas de la talla de Pablo Picasso y Salvador Dalí. Su fantasía y su memoria literarias lo reencuentran con sus ficciones, con las obras que ha amado.

Si, como el personaje de este filme, tuviéramos la oportunidad de viajar a través de nuestros autores, obras y personajes entrañables, ¿quiénes acompañarían nuestro recorrido?, ¿cuál es el potencial imaginativo que nos otorgan los libros que han hecho parte de nuestra vida lectora? y iqué sentido tienen para un docente las obras que ha habitado? Tan importante como la lectura de esas obras es la memoria de lo leído. No se trata de una memoria donde se almacenan grandes caudales de información o donde se consulta el nivel de erudición de ciertos personajes, a los que parece referirse el escritor Henry Miller cuando sostiene que "los hombres capaces de referir citas copiosas y exactas de los miles de libros que han leído, los que narran la trama de una novela con todos sus detalles, los que dan nombres y fechas de los acontecimientos históricos, y así sucesivamente, poseen una memoria monstruosa que siempre me ha resultado repulsiva" (2003, pp. 11-12). Lejos de una memoria erudita con olor a suficiencia y pedantería, se trata de una memoria vital cuyo poder evocador proporciona nuevas comprensiones del mundo, de la condición humana, de los seres y las cosas.

La memoria literaria del maestro, además de devolverlo a los textos que han pasado por su experiencia como lector, evoca los sujetos, los dispositivos escolares, los caminos, las metodologías, los espacios y las intencionalidades que han hecho parte de dicho proceso. Esa memoria se convierte entonces en una biblioteca donde aquel puede confrontar su trabajo pedagógico con lo vivido en su propia experiencia de formación literaria. Así las cosas, "el trabajo de la memoria no consiste en traernos a la mente la fotografía de los acontecimientos del pasado archivados objetivamente, sino más bien en volver a captar el significado, el sentido y las emociones a las que dichas experiencias o acontecimientos se asociaron entonces" (Bárcena \& Mèlich, 2000, p. 29).

En este sentido, la memoria literaria tiene el poder de resignificar y dejar oír nuevas voces en las lecturas de un pasado que retorna, que es presente activo. Toda relectura es un intenso acto de recordación y reelaboración. ¿Qué tendrían que recordarnos y redecirnos, por ejemplo, la niña que descendió por una madriguera y se abandonó a las potencialidades de un mundo onírico, el muñeco de madera que tuvo que vivir múltiples aventuras para dejar de ser una marioneta, la niña de figura desaliñada que enfrentó a los hombres grises y le devolvió el tiempo a los hombres, el caballero andante que todavía sigue transitando en sus múltiples lectores, el héroe que retornó a Ítaca tras su periplo existencial, el hombre que descargó su hacha en la humanidad de una usurera? Estos personajes son más
Descripción del artículo | Article description | Description de l'article | Artigo descrição

A partir de su experiencia como profesoras de literatura y práctica pedagógica, las autoras construyen un artículo de reflexión donde se centran en la memoria y la experiencia y su relación con la formación literaria. En este abordaje se enfatiza en la importancia de la memoria literaria del maestro, en la experiencia de la lectura como posibilidad de establecer un vínculo significativo con la obra literaria y en algunos caminos posibles para la orientación de las prácticas de enseñanza de la literatura en el contexto educativo. 
que nombres: son nombres con cuerpo, son nombres en nuestro cuerpo y cuerpo en nuestros nombres. ¿Pero cuál es la génesis de esa memoria que nos ha legado nombres y cuerpos vivos?, ¿cuándo empezamos a instalarnos en un mundo literario que libera y captura, que corre el velo de los ojos o enceguece, que acaricia o fractura?

Y todo comenzó cuando había una vez... cuando en nuestros primeros años un rostro llamado madre o padre, hermano, maestro o amigo nos reveló el secreto de las letras y su cantera de posibilidades. Descubríamos los juegos lúdicos de la palabra en los trabalenguas, en las adivinanzas, en las rimas. Nos acercábamos a las formas más elevadas del pensamiento y la sensibilidad a través de la poesía. Construcciones narrativas llenas de ficción y suspenso ganaban nuestra atención y nuestro tiempo. Una de las más exquisitas era el cuento, ese género literario que, desde tiempos inmemoriales, ha estado presente en múltiples experiencias humanas, como lo expresa León Felipe (2007) en este bello poema:

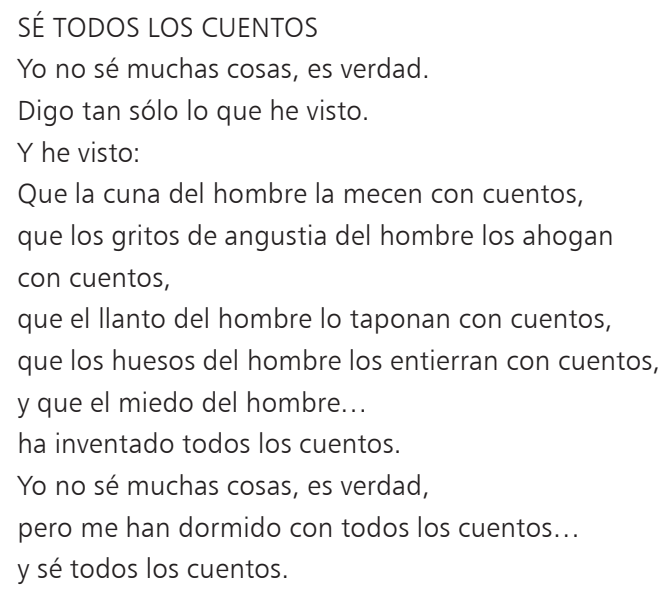

Con esa presencia irrenunciable de los cuentos empezamos a construir ese "territorio imaginario" del que habla Graciela Montes (1999) en su texto "Sherezada o la construcción de la libertad". Dicho territorio se va construyendo gracias a un pacto de ficción que suspende la incredulidad y crea tiempos y reglas distintos a los que imperan en el mundo racional y pragmático. Para la autora, su abuela fue la Sherezada de su infancia: la misma que con sus hilos verbales fue hilvanado la memoria literaria de su nieta y con ella toda una gama de sentidos y momentos vitales que posteriormente le sirvieron de plataforma para su oficio de escritora.

También el maestro de literatura está invitado a darse el permiso de irrumpir en la formación de sus estudiantes como esa abuela donadora de historias, como la Sherezada que prolonga la vida en la palabra, como aquel que acude a lo más selecto de su universo literario para implicar a sus estudiantes en un "territorio imaginario" donde sea posible levantar el vuelo del pensamiento, la sensibilidad, el deseo, la curiosidad.

La experiencia de vivir la literatura e invitar a vivirla implica dejarse ser en ella, como lo logran algunos personajes de la obra Fahrenheit 451 de Ray Bradbury (1976), posteriormente llevada al cine por el director Francois Truffaut. Entre esos personajes sobresale la figura de Montag, un bombero que, tras ejercer el oficio de perseguir lectores y quemar libros con su devastador lanzallamas, descubre en esas páginas amenazadas por el fuego letal un legado que más tarde defenderá con arrojo. Entonces el gesto que antes lanzaba a la pira un sinnúmero de ejemplares del patrimonio literario de la humanidad ahora trata de preservar, a través de una 
memoria resuelta, fantasiosa y sensible, los libros que antes parecían perderse en la nebulosa de un poder férreo y vertical. Tanto Montag como otros personajes salvaron sus obras literarias no solo cuando huyeron del sistema "antilibros" que los perseguía, para evitar que hubiese mentes librepensadoras y resistencias a sus posturas políticas; las salvaron también cuando las encarnaron, porque las hicieron cuerpo y memoria. Ese acto de memorizar o, dicho de otro modo, de fijar esos universos de ficción en la propia vida se traduce en el hilo de Ariadna que salvó del Minotauro a las obras de la censura y la prohibición.

Esa memoria obstinada en salvaguardar la riqueza cultural contenida en los libros invita también a recordar La bibliotecaria de Auschwitz, una obra del escritor español Antonio Iturbe (2013), en la cual Dita, una de las grandes protagonistas de la historia, se empeña en mantener viva una pequeña biblioteca que apenas cabe en su vestido. Su heroísmo radica no tanto en esta particularidad, sino en el hecho de que su misión la lleva a cabo en medio de ese temible infierno Ilamado Holocausto, donde todo lo que oliera a cultura parecía estar prohibido. Un papel similar cumple la protagonista de La ladrona de libros del australiano Markus Zusak (2007). En ella, la pequeña Liesel Meminger, junto con su amigo Max -un judío perseguido por los nazis- convierte el sótano de su casa en un laberinto de palabras donde los libros que presta inicialmente, y que luego roba, le dicen que, en medio de las bombas y la monstruosidad que azota a la humanidad de la época, aún hay espacios para la memoria, para la ensoñación, para la capacidad de fabulación. Acaso porque, como lo plantea el brasilero Antonio Cándido "no hay hombre ni pueblo que pueda vivir sin ella, esto es, sin la posibilidad de entrar en contacto con alguna especie de fabulación" (2013, p. 34).

Y nuevamente conviene decir que, como Sherezada, Montag, Dita y Liesel, el maestro de literatura está llamado a hacer memoria de la literatura y a hacer de la literatura una memoria donde sus discípulos encuentren los hilos de Ariadna para sus laberintos existenciales.

\section{De la memoria a la experiencia: una pregunta por los sujetos de la educación}

El héroe trágico de Sófocles en Edipo rey, que no deja de causar asombro y conmoción, conduce a reconocer las relaciones entre el deseo, el saber y la ignorancia que se tejen en el argumento de esta obra dramática. Edipo "pudo desvelar el enigma de la esfinge, respondió a la pregunta por el hombre, sin que supiera sobre sí mismo" (Giraldo, 2013). Edipo sabe, responde y acierta y por ello es proclamado rey de Tebas. En medio de otros enigmas a los que debe responder como gobernante, surge también una pregunta por su ser, vinculada a sus orígenes. Buscando y encontrando respuestas, pasa de la soberbia a la humillación, de la gloria al destierro, de rey a mendigo. Lleva hasta sus últimas consecuencias su deseo de saber, lo que le implica que ya no pueda verse impávido en el cristal o impasible en el espejo de los otros.

Esta tragedia griega se actualiza en la obra cinematográfica Incendies de Denis Villeneuve (2010), basada en la obra de teatro del mismo nombre, del dramaturgo libanés Wajdi Mouawad. Ella presenta una búsqueda decidida que arroja comprensiones impresionantes y desgarradoras. Jeanne y Simón son dos gemelos que reciben una carta que su madre les ha escrito antes de morir, mediante la cual los insta a que busquen a un padre que creían muerto y a un hermano cuya existencia ignoraban. De esta manera emprenden un viaje hacia sus orígenes, del cual no regresarán siendo los mismos.

Estas obras exponen unas relaciones entre la información, la de-formación y la trans-formación. En ellas hay una pregunta que moviliza un viaje, un deseo que no da tregua y, finalmente, el encuentro con un saber, para el cual hubo una disposición inicial y un efecto, en términos de verdad, que implicó desplazamientos subjetivos.

La trama narrativa de estas obras aboca al concepto de experiencia como lo ha desarrollado Jorge Larrosa (2006), en particular, a los principios de subjetividad, reflexividad y transformación que derivan de ella. De subjetividad, porque el lugar de la experiencia es el sujeto; de reflexividad, porque la experiencia supone un movimiento de ida y de vuelta, de salida de sí mismo hacia el encuentro con un acontecimiento que es de una radical alteridad; de regreso, pues tal acontecimiento tiene efectos en lo que se es, se piensa, se quiere y se siente (Larrosa, 2006, p. 45); y de transformación, porque la experiencia da otras formas a las palabras, ideas y sentimientos del sujeto, que se dispone en su vulnerabilidad y sensibilidad a su propia metamorfosis.

Estas referencias sobre experiencia, travesías, deseo de saber y transformación, de las que nos da cuenta el arte en su expresión literaria y cinematográfica, llevan a formularnos la pregunta acerca de las posibilidades de vivir la lectura literaria como una experiencia: ¿Es posible su emergencia en el escenario escolar? Si, en cuanto subjetiva, la experiencia de la lectura está vinculada con las propias búsquedas, con las preguntas que trabajan en cada sujeto (Zuleta, 2010), ise puede, acaso, proponer la lectura de un texto literario como una experiencia?

Es claro que la experiencia de la lectura es absolutamente singular; de ahí que un texto literario pueda ser para un sujeto una experiencia de transformación, 
mientras que para otro represente solo un libro más que llega a engrosar su enciclopedia cultural. Si bien no desconocemos que la experiencia de la lectura se fundamenta en la relación íntima entre el texto y la subjetividad (Larrosa, 2006), no por ello desestimamos el poder de agenciar que tiene el maestro para crear las condiciones de posibilidad que permitan vivir la lectura como una experiencia y con ello redescubrir a sus estudiantes en las posibilidades del devenir.

Nuestra posición al respecto es que el maestro, cuando despliega su memoria literaria y con ello la relación íntima que ha establecido con sus textos preferidos; cuando comparte su experiencia de lectura, sin ánimo de imponer o dogmatizar; y cuando lee de manera pausada, degustando los detalles de las obras, compartiendo y permitiendo la emergencia de interpretaciones, genera con ello condiciones para que otros se acerquen a las obras literarias y puedan vivirlas, quizás, como una experiencia.

La experiencia de la lectura no se garantiza; de hecho, ella se mueve en el terreno de lo incierto, de lo confuso, de lo mutable. La certeza no es su correlato, sino su antítesis. La producción de sentido que la acompaña y el poder de conmover, es decir, de afectar al sujeto en su humanidad, será siempre, en cada caso, singular. La lectura, por ejemplo, de una novela como Ensayo sobre la ceguera de José Saramago puede ser para unos un libro entretenido que no genera mayor involucramiento, pero para otros puede ser toda una experiencia.

Ante la imagen de sus ojos muertos, de una ceguera blanca como la que relata Saramago en esta novela, Manuel siente la emergencia de la angustia. Es tal la pasión que siente por la literatura, por recorrer los lugares que ella describe, por encarnar las vivencias y sentimientos de los personajes, por transportarse a otras épocas y contextos con tan solo deslizar su mirada por la tinta que recubre las palabras, que afirma que su vida no tendría sentido si no pudiera leer. Este adolescente de 17 años dice que lo llegó a habitar el miedo de pensar que al cerrar esta apoteósica novela sus ojos quedaran viendo un mar de leche. $Y$ es que para Manuel la literatura representa su vida y su modo de vivir.

Casos como el de Manuel ocurren con poca frecuencia en el contexto escolar. De hecho, parece que la realidad confirmara lo contrario: una apatía generalizada por los libros. Y nosotros, maestros, al modo de la ondulación de las olas, nos movemos en el vaivén de la idea de que a los estudiantes no les gusta leer, de que en ellos hay un cerrojo a la literatura. Intentamos explicar este hecho a la luz de muchas circunstancias: que la familia no acompaña, que los medios de comunicación los sustraen de lo esencial, que la sociedad de consumo los consume. Y sí, es cierto, estas variables tienen su incidencia, pero pocas veces interrogamos aquello que quizás sea lo único sobre lo que podemos actuar: nuestras prácticas pedagógicas (Pennac, 2008).

Pensar nuestro quehacer docente pasa, como dice Araceli de Tezanos (2012), por formularnos las preguntas qué, cuándo y cómo enseñar; para nuestro caso, qué literatura leer en las aulas escolares, y cuándo y cómo hacerlo. Pero pasa también por ver si los intereses afectivos y vitales de los estudiantes se ven representados en nuestras elecciones para ellos o si, por el contrario, como indica Philippe Meirieu, a fin de cuentas nos importa poco saber "qué les interesa", pues nuestra determinación educativa se ve respaldada por la certidumbre de obrar "por su interés" (2007, p. 36).

La pregunta por los estudiantes, muchos de ellos aburridos en las aulas escolares, es también una pregunta por su cultura, por sus saberes, por sus narrativas y por la época digital en la que se encuentran; es una pregunta que trasciende cualquier par simplificador que concibe a los 
adolescentes, por ejemplo, según representaciones negativas (como una generación poco comprometida, fascinados por la moda, la violencia, el alcohol, las drogas, etc.) o según estereotipos idealizados (magos y genios de la tecnología) (Bombini, 2006, p. 29). Es una pregunta que, por el contrario, se preocupa por reconocer sus singularidades como individuos y como sujetos sociales y culturales (Roth, 1970; Freire, 2010).

En efecto, pensar la enseñanza de la literatura en particular y el acto educativo en general supone reinventar la mirada de los sujetos destinatarios de la educación y reconocer que nuestros jóvenes no son los mismos de hace 10 años. Para ellos, dar de comer a una vaca es algo tan exótico como para sus abuelos el mundo del Internet (Serres, 2013). Pero pasa también por reconocer que, pese a las diferencias generacionales, su condición humana está hecha de la misma arcilla de todos: de miedos, deseos, lenguaje, amores, odios, etc., a la que cada época y cada persona le da una forma distinta.

Somos sujetos hechos de palabras y, como tales, con una sed de relatos y una necesidad inconmensurable de contar y de que nos cuenten. Esto es un punto a nuestro favor en la tarea de formar en y por medio de la literatura. Pero entonces, ¿por qué algunos estudiantes ven los libros como muros impenetrables que los separan de la vida?, ¿por qué hay pocos Manueles en las aulas escolares a los que les guste leer y lo degusten?, ¿será que la lógica interna de los libros que les proponemos no se adecúa a su lógica afectiva e intelectual?, ¿será que, como dice Pennac (2004), no estamos dando de leer? Si la literatura es una metáfora de la condición humana, si bordea los problemas fundamentales de los hombres y si es estructural la necesidad de que nos relaten -que se remonta a nuestra infancia-, entonces es posible concluir que por medio de nuestras prácticas pedagógicas podemos quitar ese cerrojo que se pone sobre los libros, para mostrar todo un horizonte literario e incitar a transitarlo.

Los profesores no compartimos solo el saber con nuestros estudiantes, sino el propio deseo de saber. $Y$ este deseo puede sembrar o despertar en ellos el deseo por leer. Es la pasión del maestro por la literatura, es su vinculación íntima con la cultura, de lo que, en última instancia, da cuenta su memoria literaria. Esa pasión por las letras que aflora por los poros, que se aferra a la entonación como el óxido al hierro, cuando se da de leer, que descubre el amor literario en el resplandeciente brillo de unos ojos que leen, esa pasión posibilita abrir caminos a una relación de los estudiantes con la literatura. Es la memoria literaria la que facilita pensar la enseñanza de la literatura, su didáctica, que, dicho sea de paso, debe distinguirse de la didáctica de la lengua.

Ahora bien, la falta de lectura de nuestros estudiantes, como lo recuerda Pennac (2004), solo se "cura" leyendo; la no comprensión, con la inmersión en el texto; la apatía por los libros, con un acercamiento a estos, con los que se pueda degustar el sabor que contienen las palabras, en su dulzura, pero también en su amargura y, finalmente, en su vinculación con nuestra inquietante y sufriente humanidad. Ya lo decía Meirieu: la literatura nos posibilita

... el reconocimiento de lo fundamental, el descubrimiento de nuestros interrogantes comunes. No suele proponer respuestas, pero nos devuelve la imagen de lo que hemos sido, somos o podríamos ser. Nos permite decirnos, explicarnos por medio de historias lejanas de otros seres humanos en los que, precisamente, porque son diferentes de nosotros, podemos reconocernos y a través de los cuales podemos cuestionarnos sin ponernos en peligro (2007, p. 103). 
Internarnos en historias lejanas -y, por ello mismo, cercanas-, hablar de nosotros por medio de otros seres y reconocernos en ellos como en un traslúcido espejo es hacer, como decía san Juan, que el verbo se haga carne, que el saber se encarne, que nuestra mente se expanda por toda nuestra superficie y profundidad corporal; es, finalmente, fundar una experiencia literaria que a su vez configura la memoria literaria de cada sujeto lector.

La experiencia literaria posibilita la subjetivación de la vida misma, en la medida en que nos devuelve el reflejo de nuestra propia experiencia. Ella interviene en la construcción de la identidad de un sujeto, de ahí la necesidad de "conciliar las experiencias vitales con las experiencias literarias" (Sánchez, 2008, p. 335).

Quizás fue esta conciliación la que permitió que adolescentes del grado undécimo se hicieran también lectores de su propia vida cuando se internaron en las páginas de El Lector del escritor Bernhard Schlink (2000). El encuentro y desencuentro amoroso que se vive en esta novela, la emergencia del amor y de la sexualidad aloerótica', el tránsito del niño al hombre, los sobornos íntimos, los dilemas escolares, las dinámicas familiares, el desasimiento de la autoridad parental, las elecciones profesionales, entre otros, son asuntos que tocan momentos vitales en los adolescentes y que les permiten reconocerse en las inquietudes del protagonista. "Menos mal no he tenido agresiones físicas con mi pareja, pero sí he sentido que no estamos el uno para el otro", dice un estudiante a propósito de los ecos que esta novela trae a su vida, en particular, de la escena en la que Hanna revienta el labio de Michael al pegarle con una correa. La comprensión de Michael de que los hijos no tienen que ser la prioridad de su padre le permite también a una joven situarse en esta divergencia con respecto a su madre, "para que entendiera que yo no soy lo que ella piensa".

La experiencia de la lectura entraña una relación particular con un texto, de ahí que, como plantea Larrosa, lo importante desde el punto de vista de la experiencia no es lo que dice el libro, en este caso El lector y Ensayo sobre la ceguera, sino el modo cómo, en relación con la trama de la novela y la posición del narrador, el sujeto lector puede formar o transformar sus propios pensamientos, puede sentir lo que aún no sabe sentir o puede transformar los modos de enunciarse y su propio lenguaje; en definitiva, lo esencial desde la perspectiva de la experiencia es cómo la lectura de un texto puede, finalmente, permitirle a un sujeto hablar por sí mismo, escribir por sí mismo, en primera persona y con sus propias palabras (2006, p. 50).

La experiencia literaria nos permite, pues, reconocernos, subjetivarnos y tomar decisiones, cuando ella toca la fibra de nuestra alma, cuando nos captura en nuestras inquietudes y angustias, cuando nos permite viajar para ser otros, como dice Manuel, y, al mismo tiempo, regresar para seguir siendo nosotros mismos, aunque a la vez distintos.

\section{Tras los sentidos del laberinto o los posibles de la literatura en el aula}

En su libro La experiencia de la lectura: estudios sobre literatura y formación, Jorge Larrosa (1998) plantea que la función del profesor es "mantener viva la biblioteca como espacio de formación. Y eso no significa

1 Expresión utilizada en el psicoanálisis para designar una actividad sexual que encuentra su realización y satisfacción en el vínculo con otra persona, en oposición al autoerotismo. 
producir eruditos o prosélitos o, en general, personas que saben, sino mantener abierto un espacio en el que cada uno pueda encontrar su propia inquietud" ( $p$. 33). Tres ideas importantes se desprenden de esta afirmación: el papel del docente de literatura, las posibles intencionalidades de su accionar didáctico y el papel del estudiante en la experiencia de acercamiento a los libros. Frente a estos aspectos surge un interrogante: ¿qué condiciones de posibilidad puede crear el maestro en el aula para convertir su biblioteca y la biblioteca de sus educandos en un espacio vital para la formación literaria?

Los ejemplos citados en relación con la presencia en el aula de obras como Ensayo sobre la ceguera y El lector testimonian la apuesta de mantener vivas dichas bibliotecas, de encender deseos insaciables de literatura. La llama de estos deseos se atiza con ejercicios de intertextualidad en los que el texto literario entra en diálogo con múltiples discursos culturales, sean literarios o no, pertenezcan al código lingüístico o no. En este orden de ideas, el cine, la pintura, el teatro, la música, la danza, se constituyen en interlocutores de la palabra hecha arte, pero al mismo tiempo se ofrecen como formas artísticas que posibilitan la expresión de una experiencia literaria. ¿No es acaso una manera sumamente creativa la interpretación de obras narrativas a través de un museo literario, en el que cada lector encarna el personaje leído?, ¿no son algunas canciones un texto poético y la misma poesía, una melodía muchas veces por nosotros entonada? No obstante, el tratamiento que se le dé a cada obra literaria depende en primer lugar de su inmanencia; en palabras de Fernando Vásquez Rodríguez, "es la obra literaria la que condiciona la elección del método" (2006, p. 100).

Las distintas posibilidades que permite la literatura admiten una única condición y es que se abra un espacio de lectura e interpretación en las propias aulas escolares. La lectura silenciosa, la lectura compartida, la lectura dramática, la relectura, la lectura sin afanes: que se detenga en el detalle, que sopese cada palabra y que, como catador de vino, permita a cada lector saborearla. El maestro acompaña esta lectura desde su experiencia y memoria literarias, pero también en el ejercicio de dar de leer, es decir, regalar desde la orquesta de su garganta una seductora melodía para conducir a sus alumnos, como el flautista de Hamelín, hacia los lugares más insospechados de la imaginación humana.

Una pregunta personal, íntima, tímidamente agazapada en los recovecos del crecimiento es también a veces una estrategia para leer, para tejer ideas que permitan a cada sujeto construir su mundo y su lugar en él. Tal vez la literatura no dé respuestas, pero sí abre muchas puertas al pensamiento, muchos modos para ser otros. Así, esta conciliación entre las experiencias vitales y una obra que permita pensar aquellas se constituye en un terreno fértil para sembrar inquietudes y deseos de leer.

Allanar este terreno es uno de los mayores retos para maestros y escuela. No resultará fecundo si, en lugar de espacios para la formación literaria, se privilegian prácticas orientadas a la información literaria, a la ingestión de un cúmulo de datos que atiborran, pero no nutren. Ni la memoria vital y perpetuadora ni la experiencia multisensible y transformadora tendrán asidero, si la riqueza estética y cultural de las obras sucumbe ante el asedio -aún no exiliado de las escuelasde ejercicios orientados a enseñar gramática a través de los textos literarios. Tampoco serán prometedoras las salidas de este laberinto de sinsentidos, si la oferta más publicitada por parte de maestros y estudiantes se agota en los célebres y rentables libros de autoayuda.

Estas orientaciones en poco contribuirán a que en la escuela los estudiantes puedan acceder, como sostiene Antonio Cándido (2013), al derecho a la literatura. Derecho al que, según el autor, deben tener acceso todos los grupos culturales, independientemente de su origen o estratificación social. Para el autor, la literatura es un bien tan imprescindible como los bienes materiales que aseguran la supervivencia. Es un bien espiritual que contribuye a la humanización:

Entiendo aquí por humanización [...] el proceso que confirma en el hombre aquellos rasgos que consideramos esenciales, como el ejercicio de la reflexión, la adquisición del saber, la buena disposición para con el prójimo, la depuración de las emociones, la capacidad de penetrar en los problemas de la vida, el sentido de la belleza, la percepción de la complejidad del mundo de los seres, el cultivo del humor. La literatura desarrolla en nosotros la cuota de humanidad en la medida que nos vuelve más comprensivos y abiertos a la naturaleza, a la sociedad y a nuestros semejantes (p. 44).

Así, pues, la literatura, como posibilidad de humanización, como bien cultural y derecho inalienable en términos de Cándido, reclama una concepción y un abordaje distintos en el escenario educativo. Lo distinto se entiende acá como las rupturas y discontinuidades que se podrían llevar a cabo para combatir posturas y prácticas que en nada han favorecido la enseñanza de la literatura. Concederle a esta un lugar poblado de sentido implica para el maestro, por ejemplo, "buena orientación" para discernir sobre aquello que lee e invita a leer (Henríquez Ureña, 2002, p. 15), para provocar y proponer hipótesis de lectura (Jurado, 2001, p. 94), para invitar a amar la literatura desde el testimonio personal (Machado, 2002, p. 33). Y, sobre todo, es preciso entender que 
La enseñanza de la literatura no consiste solo en dictar clase; es una labor múltiple de orientación y de ampliación de los horizontes de la lectura y de la escritura, de cultivo de la sensibilidad y la imaginación, de desarrollo de la interpretación y de la argumentación, de orientación del ejercicio de la libertad, del distanciamiento necesario de lo utilitario de la realidad, del juego con las posibilidades del mundo, de desarrollo de las dimensiones humanas y de rescate de la dignidad de la persona (Cárdenas, 2004, p. 43).

Lo anterior pone de relieve el carácter dinámico, reflexivo y propositivo que reclama la didáctica de la literatura. No se habla aquí de una didáctica que se resuelve en recetarios, en clases divertidas o en desfiles de actividades sin suelo conceptual; hablamos de un campo discursivo que problematiza el saber, el hacer y la subjetividad del docente; de un ámbito de reflexión que se pregunta por el sustento epistemológico y ontológico de aquello que se enseña y se aprende; de un escenario que repiensa la formación en atención a los contextos políticos, sociales e institucionales donde se lleva a cabo la labor educativa. La consolidación de este campo didáctico es tan exigente como necesaria para alentar procesos que acentúen los posibles de literatura en la formación y en la vida de los estudiantes.

Y, no obstante el pesimismo que parece revolotear en las escuelas, la vocación desahuciada de algunos educadores, la sospechosa indiferencia de muchas instituciones, el lugar de lo posible sigue tan vital como ayer, como hace años, quizás décadas. Conviene dejarse provocar por el poema "Nudo" (2003) de José Manuel Arango, para decir, con la voz poética:

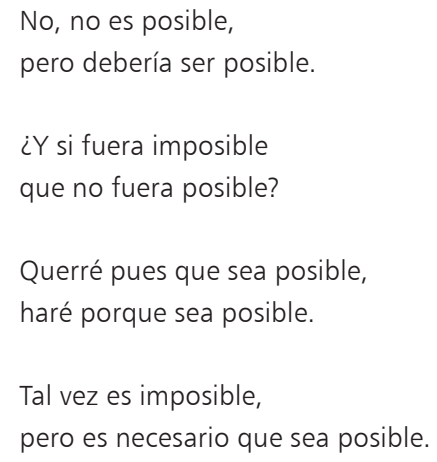

En estos versos aletean la incertidumbre, la pregunta, el nudo que lleva a titubear, pero también el deseo y el hacer que conducen a lo posible. Si hay un lugar para lo posible en el abordaje de la literatura en el escenario educativo, entonces expresiones tan recurrentes como "esos muchachos no leen", "ellos dicen que la literatura no sirve y no voy a insistir más", "van a perder lengua castellana si siguen leyendo así", irán abandonando paulatinamente el vocabulario de los docentes. Y como palabra y acción forman un maridaje indisoluble, puede ocurrir que, una vez resignificado el vocabulario de los maestros, también los estudiantes empiecen a otorgar nuevos sentidos a su palabra y a sus memorias y experiencias literarias. Entonces puede suceder también que, como la protagonista del cuento "Felicidad clandestina" de la escritora Clarice Lispector, conviertan la obtención de un libro en una de sus grandes obsesiones, o puedan reclamar acaso, como Hanna Smith, la protagonista de El lector, la presencia asidua de rituales de lectura que les regalen banquetes de libertad.

Vale la pena, entonces, seguir habitando el laberinto, para ser otros en los hilos de la memoria, la experiencia y la formación... 


\section{Sobre las autoras}

Érica Areiza-Pérez es magíster en Literatura Colombiana. Licenciada en Educación Básica con Énfasis en Humanidades, Lengua Castellana. Profesora de la Facultad de Educación, Universidad de Antioquia, en pregrado y posgrado. Integrante del grupo de investigación Somos palabra: Formación y contextos.

Diela Bibiana Betancur-Valencia es magíster en Investigación psicoanalítica. Licenciada en Educación Básica con Énfasis en Humanidades, Lengua Castellana. Profesora de la Facultad de Educación, Universidad de Antioquia, en pregrado y posgrado. Integrante del grupo de investigación Somos palabra: Formación $y$ contextos.

\section{Referencias}

Giroux, H. (1990). Los profesores como intelectuales. Barcelona: Paidós.

Henríquez Ureña, P. (2000). Aspectos de la enseñanza literaria en la escuela común. Hojas de lectura, 55, 14-21.

Iturbe, A. (2013). La bibliotecaria de Auschwitz. Bogotá: Planeta.

Jurado Valencia, F. (2001). La literatura como provocación hacia el conocimiento en la educación. En Escritores, profesores y literatura: ponencias. Foro Internacional Uneda. Bogotá: Plaza \& Janes, Universidad Nacional de Colombia, Pontificia Universidad Javeriana.

Larrosa, J. (1998). La experiencia de la lectura: estudios sobre literatura y formación. Barcelona: Laertes.

Larrosa, J. (2006). Sobre la experiencia. Revista Educación y Pedagogía, separata ¿Y tú qué piensas? Experiencia y aprendizaje, pp. 43-67. Universidad de Antioquia, Facultad de Educación. Medellín: Artes y letras.

Leon, F. (2007). Sé todos los cuentos. Papel en Blanco. Recuperado de http://www. papelenblanco.com/poesia/leon-felipe-se-todos-loscuentos

Lispector, Cl. (1998). Felicidade clandestina. Rio de Janeiro: Rocco.

Machado, A. M. (2000). Entre vacas y gansos: escuela, lectura y literatura. Hojas de Lectura, 55, 30-37.

Meirieu, P. (2007). Frankenstein educador. Barcelona: Laertes.

Miller, H. (2003). Los libros en mi vida. Leer y Releer, 33, 4-54. Sistema de Bibliotecas, Universidad de Antioquia. 
Montes, G. (1999). La frontera indómita: en torno a la construcción y defensa del espacio poético. México: Fondo de Cultura Económica.

Pennac, D. (2004). Como una novela. Trad. Moisés de Melo. Bogotá: Norma.

Pennac, D. (2008). Mal de escuela. Trad. Manuel Serrat Crespo. Bogotá: Mondadori.

Roth, H. (1970). El buen arte de la preparación de la clase. Revista Educación, 1, 26-36.

Sánchez Corral, L. (2008). De la competencia literaria al proceso educativo: actividades y recursos. En A. Mendoza Fillola (comp.), Didáctica de la lengua y la literatura en primaria. Madrid: Pearson.

Saramago, J. (2006). Ensayo sobre la ceguera. Bogotá: Punto de Lectura.

Schlink, B. (2000). El lector. Trad. Joan Parra Contreras. Barcelona: Anagrama.

Serres, M. (2013). Pulgarcita. Trad. Luis Alfonso Palau. Recuperado de http:// $w w w . g o o g l e . c o m . c o / u r l ? s a=t \& r c t=j \& q=\& e s r c=s \& f r m=1 \&$ source $=$ we $\mathrm{b} \& \mathrm{~cd}=1 \& \mathrm{sqi}=2 \& \mathrm{ved}=0 \mathrm{CCOQFjAA \& url}=\mathrm{http} \% 3 \mathrm{~A} \% 2 \mathrm{~F} \% 2 \mathrm{Fmaescen}$. medellin.unal.edu.co\%2Findex.php\%2Fcomponent\%2Fjoomdoc\%2Fdoc download\%2F102-la-pulgarcita\&ei=n00wU6y0AdC0kQff3IDwBA\&usg =AFQjCNEy546_5VDsNPvm80bBvaWkROKHEQ\&sig2=oah4NIYs4pSJF ri-7ucR8Q\&bvm $=$ bv. 62922401 , d.eW0

Sófocles (2005). Edipo rey. Bogotá: Modadori.

Vásquez Rodríguez, F. (2008). La enseña literaria. Crítica y didáctica de la literatura. Bogotá: Kimpres.

Zuleta, E. (2010). Sobre la lectura. Leer y Releer, 58, 6-35. Sistema de Bibliotecas, Universidad de Antioquia.

Zusak, M. (2007). La ladrona de libros. Barcelona: Mondadori.

\section{Filmografía}

Truffaut, Francois (dir.) (1996). Fahrenheit 451. Reino Unido: Universal Pictures \& Vineyard Production.

Villeneuve, D. (dir.) (2009). Incendies. Canadá: Alta Films.

Woody Allen (dir.) (2011). Medianoche en París. Estados Unidos \& España: Gravier Productions \& Mediapro. 